\title{
Agroecologia, relações produtivas e de gênero na agricultura familiar: o estudo de caso da Associação de Produtores Agroecológicos Sementes do Futuro de Atalanta - SC
}

\author{
Agroecology, gender and productive relations in the familiar agriculture:The study of the case of the \\ Sementes do Futuro (Seeds of the Future) Agroecologic Producers from Atalanta - SC
}

\section{Adilson Tadeu Basquerote Silva}

Universidade do estado de Santa Catarina - UDESC - Florianópolis - Santa Catarina - Brasil

\section{Rosemy da Silva Nascimento}

Universidade Federal de Santa Catarina - UFSC - Florianópolis - Santa Catarina - Brasil

\section{Jardel Gores}

Universidade de Santa Cruz do Sul - UNISC - Santa Cruz do Sul - Rio Grande do Sul - Brasil

Resumo: As transformações ocorridas na agricultura familiar nos últimos quarenta anos têm incitado estudos do ponto de vista social, intelectual e no campo político. Entre as perspectivas enfocadas destacam-se a reprodução social, as políticas públicas, a sucessão da propriedade familiar, as relações de gênero, as relações produtivas, entre outros. Nesse cenário, a agroecologia vem sendo considerada uma alternativa de geração de renda e de fixação das populações no campo, de manutenção das relações produtivas, por meio de melhoria das condições de vida renda e de trabalho. Ela tem promovido alterações nas relações de gênero e rearranjos familiares à medida que o trabalho feminino deixa de ser invisibilizado. Nesse contexto, este estudo objetiva analisar a importância da agroecologia como promotora de equidade de gênero e de manutenção das relações produtivas na agricultura familiar agroecológica da Associação de Produtores Agroecológicos Semente do Futuro (APASF) do município de Atalanta (SC). Para isso, foi realizada uma pesquisa qualitativa de caráter etnográfico, com base na coleta de dados por meio de entrevistas não estruturadas, além da observação participante, realizada com homens e mulheres, membros da Associação. Segundo os relatos, a agroecologia promoveu mudanças na organização familiar, na posição de gênero dentro da Associação e reposicionou as mulheres nas propriedades e nas relações familiares. Além disso, manteve as relações produtivas no campo por meio da geração de renda e da permanência das famílias no meio rural. Por fim, as ações futuras da Associação envolvem homens e mulheres e evidenciam que é possível igualdade de gênero na agricultura familiar.

Palavras-chave: Agricultura. Agroecologia. Gênero.

\begin{abstract}
The transformations occured in the familiar agriculture in the last fourty years has incited studies in the political, intellectual and social areas, In the on focus perspectives we can find the social reproduction, the public policy, the succession of the family property, the gender relations, the productive relations, among others. In the scenery the agroecology has been concidered an income generator alternative, it has keeping the families in their farms and also mantaining the productive relations through improvements in life, income and work. It has promoted family rearragements as the female labor ceases to be made invisible. In this context, this study aims to analyse the importance of the agroecology as gender equity promoter and maintaining productive relations in family farming. Atalanta, SC, Sementes do futuro (seeds of the future), (APASF) producers association agroecolic. For such, it was conducted a ethnographic qualitative survey based on the datas collecting through unstructured interviews and participant observations carried on men and women, association members. According
\end{abstract}


to reports, the agroecology promoted changes in the familiar organization, the position of gender in the association, replaced women in the properties and in the family relations. Although, it maintened the productive associations in the countryside through the income produce and the families permanece in the countryside areas. Lastly, the future association plans involve men and women and it shows that is possible equality gender in family farming.

Keywords: Agroecology. Agriculture. Gender.

Ágora [ISSN 1982-6737]. Santa Cruz do Sul, v. 17, n. 2, p. 131-143, jul./dez. 2015. 


\section{Introdução}

O presente estudo se propõe a analisar a importância da agroecologia como promotora de equidade de gênero e de manutenção das relações produtivas na agricultura familiar agroecológica da Associação de Produtores Agroecológicos Sementes do Futuro (APASF) do município de Atalanta (SC).

Este mesmo trabalho também é resultado de uma extensa pesquisa em parceria, e parte integrante da dissertação de um dos autores aqui apresentados; Adilson Tadeu Basquerote Silva, Mestre em Planejamento Territorial e Desenvolvimento Socioambiental pela Universidade do Estado de Santa Catarina, (UDESC). Ainda sobre a presente pesquisa, e entre as possíveis e posteriores reflexões, análises e resultados, destacamos que o trabalho foi apresentado no VII Seminário Internacional de Desenvolvimento Regional, em Santa Cruz do Sul, no ano de 2015.

Contudo, estamos por apresentar reflexões frente à sociedade globalizada, sociedade esta que criando ou "fortalecendo determinadas verdades" impossibilita um olhar e a própria valorização sobre diferentes experiências e práticas regionais, haja vista a própria dinâmica da agricultura familiar e seu caráter ímpar.

Historicamente, a agricultura familiar representa uma fonte de renda para milhares de agricultores que no trato da terra buscam o sustento para a família. Esse sistema produtivo vem passando por significativas mudanças em sua composição, estrutura e relações de produção. Percebe-se, entre outros aspectos, que além de haver um desinteresse das populações envolvidas em permanecer no campo, em especial por parte dos mais jovens, verifica-se a existência de uma atuação cada vez maior das mulheres em todas as etapas no processo de produção, comercialização e gestão do excedente.

O processo de modernização da agricultura brasileira pretende transformar a agricultura de insumos tradicionais em agricultura de insumos modernos, sem considerar a organização, a capacidade e os limites dos ecossistemas locais, bem como a forma de organização e os conhecimentos tradicionais das populações envolvidas. Diante desse cenário a agricultura familiar resiste, buscando formas de manter as relações de produção, a sucessão geracional e gerar excedente mínimo para a subsistência de seus membros.

O termo "agricultura familiar", apesar de controverso, ganha legitimidade a partir dos anos de 1990 mediante um processo que envolve questões políticas e acadêmicas. Conforme indica Schneider (2003), na esfera política, o termo emerge como categoria utilizada pelos movimentos sociais no campo, vinculados ao sindicalismo rural ligado à Central Única Trabalhadores (CUT) e à Confederação Nacional dos Trabalhadores na Agricultura (Contag). Ainda segundo Schneider (2003), essas organizações se valem do termo para defenderem seus interesses frente à constituição do Mercado Comum do Sul (Mercosul).

Ao longo da década de 1990, o termo passou a agrupar um amplo leque de movimentos que reivindicavam políticas de preço e crédito diferenciados para os agricultores familiares. Posteriormente, o termo passa a ser legitimado pelo Estado ao ser incorporado legalmente e institucionalmente à criação do Programa Nacional de Fortalecimento da Agricultura Familiar (Pronaf), em 1996, no qual foram criadas políticas de crédito específicas para o setor.

No cenário acadêmico, estudos de Veiga (1991), Abramovay (1992) e Lamarche (1993, 1998) conferem e dão visibilidade a uma forma social de agricultura. De acordo com Schneider (2003), os estudos revelaram que a agricultura familiar correspondia a uma forma de organização social legitimada e reconhecida em grande parte dos países desenvolvidos, onde o trabalho da família assume importância decisiva na estrutura agrária.

Tamanha é a importância da agricultura familiar que ela é a principal responsável pela produção de alimentos de subsistência, preservação do meio ambiente e manutenção das relações sociais no campo (SPANEVELLO, 2008). Nesse sentido, Costabeber e Caporal (2003) defendem que ela é, ao 
mesmo tempo, unidade de produção, de consumo e de reprodução; portanto, funciona mediante uma lógica de produção combinada de valores de uso e de mercadorias, buscando sua reprodução. Com sentido similar, Abramovay (1998) considera existir três atributos importantes na agricultura familiar: gestão, propriedade e trabalho familiar. Na sua definição, "a agricultura familiar é aquela em que a gestão, a propriedade e a maior parte do trabalho são provenientes de indivíduos que mantém entre si laços de sangue ou de casamento" (Abramovay 2014, p. 146). Família, trabalho e gestão também são considerados essenciais na definição de Lamarche (1998, p. 15), quando afirma que "a exploração familiar corresponde a uma unidade de produção agrícola onde propriedade e trabalho está intimamente ligado à família". Para ela, por agricultura familiar entende-se "a ideia de uma identidade entre família exploração" (Lamarche 1998, p. 18).

De maneira análoga, Wanderley (2001, p. 25) se refere à agricultura familiar como sendo "aquela em que a família, ao mesmo tempo em que é proprietária dos meios de produção (produzindo para seu consumo e para o mercado), assume o trabalho no estabelecimento produtivo".

Segundo ela, a conjugação dessas duas características - o fato de uma estrutura produtiva associar família-produção-trabalho - tem consequência fundamental na forma como ela age econômica e socialmente.

Por suas características históricas, o território catarinense abrange inúmeros agricultores familiares. Desde o processo de colonização, a base da produção agrícola catarinense foi pautada na pequena propriedade familiar, e mesmo com o intenso processo de migração do campo para a cidade, o Estado permaneceu com uma população dedicada à agricultura, vivendo próxima às pequenas cidades, numa relação rural-urbano, conforme destacado por autores como Wanderley (2011) e Veiga (2004).

De acordo com Censo Agropecuário realizado pelo Instituto Brasileiro de Geografia e Estatística (IBGE 2006), das 193.668 propriedades agrícolas do
Estado, 168 mil foram classificadas como estabelecimentos de caráter familiar, o que representa $87 \%$ do total. Deste modo, Santa Catarina aparece como destaque no percentual total de agricultores familiares em relação a outros estados. Ressalta-se que os $87 \%$ de estabelecimentos detêm apenas $44 \%$ da área estadual e produzem o equivalente a $67 \%$ do valor bruto de produção dos estabelecimentos agropecuários do território catarinense. No que diz respeito à estrutura fundiária, predominam estabelecimentos de pequenas dimensões, nos quais $65 \%$ das propriedades possuem áreas inferiores a 20 hectares e 69,3 mil estabelecimentos possuem menos de 10 hectares, 0 que corresponde a $36 \%$ do total. No ano de 2006, através dos dados contidos no IBGE, eram 570 mil pessoas ocupadas nos estabelecimentos agropecuários catarinenses.

Nesse cenário, entre os agricultores familiares é crescente a parcela de famílias que buscam alternativas produtivas no meio rural que se diferenciem do sistema convencional. Na literatura que trata sobre agroecologia os agricultores convencionais são aqueles:

(...) que aderiram ao modelo produtivista estimulados pelas políticas de modernização da agricultura iniciadas nos anos 1960, conhecida como Revolução Verde. Algumas características dos agricultores convencionais são o uso de insumos industriais, as monoculturas, uniformização genética e, geralmente, a subordinação a uma empresa que comercializa seus produtos. (CAPORAL; COSTABEBER, 2004, p. 65).

Entre os sistemas produtivos na agricultura familiar vem se destacando a agroecologia, que para Caporal, Costabeber e Paulus (2006) significa a junção da ecologia com a agronomia, da qual se leva em consideração a necessidade de conservação da biodiversidade ecológica e cultural. Corroborando os autores, Gliessmann (2001) defende que ela busca desenvolver uma agricultura ambientalmente adequada, que valoriza o conhecimento local dos agricultores, a socialização desses conhecimentos e sua aplicabilidade como objetivo comum à sustentabilidade. Desse modo, agroecologia 
incorpora ideias que vão além das fronteiras convencionais, semelhante ao que destaca Altieri:

(...) constitui uma estrutura teórica destinada a compreender os processos agrícolas de maneira ampla. Os sistemas produtivos são concebidos como uma unidade fundamental de estudo, onde os ciclos minerais, as transformações energéticas, os processos biológicos e as relações socioeconômicas são investigadas e analisadas como um todo [...] a pesquisa agroecológica preocupa-se não em maximizar a produção de uma atividade em particular, mas sim otimização do agroecossistema como um todo. Essa tendência troca a ênfase de uma pesquisa agropecuária direcionada a disciplinas e atividades específicas para tratar de interações complexas entre pessoas, culturas, solos e animais (ALTIERI, 1989, p.18) .

A agricultura de base agroecológica é apontada como uma estratégia de desenvolvimento rural, com vistas à diversificação e à dinamização do setor agrícola, além de representar uma forma de proporcionar maior agregação de valor e geração de excedente aos pequenos produtores familiares. Nesse contexto, torna-se essencial a efetiva participação de todos os membros da família no processo produtivo devido à intensidade do uso de mão de obra, realidade que abre espaço para a efetiva participação da mulher na produção, comercialização e gestão do excedente.

A perspectiva de análise de gênero em espaços rurais aponta para a questão da subordinação e subvalorização do trabalho feminino, em virtude de este ser considerado uma ajuda ao trabalho que pertence ao homem. Assim sendo, confere-se à mulher a condição de membro da família não remunerado e com atuação invisibilizada. (PACHECO, 2002; PAULILO, 1987; WOORTMANN; WOORTMANN, 1997).

Em argumento semelhante, Melo e Di Sabbato (2005) afirmam que o trabalho feminino na agricultura familiar é visto como uma extensão do seu papel de mãe, esposa, dona de casa e provedora das necessidades da família. São de sua responsabilidade o quintal, a horta, os serviços domésticos, ou seja, as atividades de reprodução. De forma inversa, para o homem cabe a posição de provedor do estabelecimento.
Quanto à coordenação do trabalho nos estabelecimentos rurais, Moura (1978), Heredia (1979) e Woortmann e Woortmann (1997) explicitam que o trabalho é coordenado pelo homem, que assume o papel de chefe do processo produtivo. Cabe a ele transmitir no próprio trabalho as dimensões simbólicas e educativas da agricultura familiar. Com essa perspectiva, Woortmann (1995, p. 11) destaca que "a transmissão do saber é mais do que transmissão de técnicas: ela envolve valores e construção de papéis". Segundo a autora, o homem é detentor de um saber que o autoriza a governar 0 processo de trabalho, isto é, a dirigir o trabalho e a família. Esse saber é transmitido à força do trabalho, aos filhos que, ao trabalhar, estão se constituindo também como "conhecedores plenos" (IBID., p. 13).

Aprofundando as discussões sobre o tema das relações sociais construídas no meio rural por meio da divisão social do trabalho, Paulilo (1987), ao descrever a organização interna das atividades agrícolas em comunidades do Estado de Santa Catarina e da Paraíba, constatou que independente do caráter e do esforço despendido, quando realizado por mulheres, geralmente o trabalho é considerado "trabalho leve" e possui menor valor de remuneração. Para ela:

(...) "trabalho leve" não significa trabalho agradável, desnecessário ou pouco exigente em termos de tempo ou de esforço. Pode ser estafante, moroso, ou mesmo nocivo à saúde - mas é "leve" se pode ser realizado por mulheres e crianças. Fica a pergunta: por que se paga menos pela realização dessas tarefas? A resposta não deve ser procurada em realidades especificadas das regiões estudadas ou do próprio meio rural como um todo. Essa situação ocorre da valorização social do homem enquanto "chefe de família", responsável pela reprodução de seus "dependentes". Assim, o trabalho desses últimos fica em plano secundário, cabendo, nestes casos, uma remuneração que apenas "ajuda" a composição do orçamento familiar (Paulilo, 198, p. 7).

Contata-se que o trabalho é "leve" (e a remuneração é baixa) não por suas próprias características, mas pela posição que seus realizadores ocupam na hierarquia familiar. (IBID., p. 7). No mesmo panorama, Sampedro Gallego (1996), ao avaliar as diferenças de subordinação entre os 
filhos homens e as filhas mulheres em relação às ordens do pai, considera que para os filhos homens o trabalho é uma situação provisória, pois futuramente eles se tornarão os chefes de família. Ao passo que, para as filhas mulheres, esta será uma condição permanente à medida que as solteiras são consideradas ajudantes do pai e quando casadas tornar-se-ão ajudantes do marido. Evidenciando, assim, a eterna condição das mulheres serem reconhecidas como ajudantes familiares e "invisíveis" do ponto de vista social.

É nesse contexto que o presente estudo analisa a importância da agroecologia como promotora da equidade de gênero e de manutenção das relações produtivas na agricultura familiar agroecológica da Associação de Produtores Agroecológicos Semente do Futuro (APASF) do município de Atalanta (SC).

\section{0 percurso metodológico - percorrendo os caminhos da APASF}

\section{A Associação de Produtores Agroecológicos} Semente do Futuro (APASF) situa-se no município de Atalanta (SC), localizado a aproximadamente $200 \mathrm{~km}$ de Florianópolis. De colonização alemã e italiana, é um município essencialmente agrícola e sua estrutura fundiária caracteriza-se pela presença de agricultores familiares com propriedades que variam entre 10 e 50 hectares (KRAEMMER, 2000).

O fim da matéria-prima para as madeireiras coincidiu com a chegada da Revolução Verde, movimento que trouxe a mecanização e os insumos químicos para a agricultura, sendo que no início dos anos de 1990, as primeiras propriedades iniciam a experiência de cultivo agroecológico.

A APASF, fundada em 1996, hoje está localizada nas comunidades de Alto Dona Luíza e Santo Antônio, no município de Atalanta, interior de Santa Catarina.

$\mathrm{Na}$ época, devido à dificuldade de transição do sistema convencional para o agroecológico, inicialmente os produtores viviam com incertezas constantes. Não havia um sistema articulado de comercialização específico para o setor, nem técnicas específicas que norteassem as atividades diárias e resolvessem os problemas decorrentes (BASQUEROTE SILVA, 2013).

Em seu estudo, Basquerote Silva (2013) descreve que a Associação se tornou referência na produção de base agroecológica no Alto Vale do Itajaí, (SC) e para outros produtores e associações, por apresentar algumas características específicas, tais como: desenvolver técnicas de cultivos peculiares, integrar-se a um sistema de comercialização competitivo, possuir uma organização interna estruturalmente organizada com marcante presença feminina, contar com uma produção diversificada e permanente, sendo referência regional e municipal na produção e difusão do sistema agroecológico. Ademais, a Associação possui participação feminina marcante nos cargos de direção.

A trajetória da APASF se constitui entre fracassos e sucessos, famílias entrando no sistema ou na Associação, outras saindo. Atualmente ela é composta por 15 membros, sendo oito mulheres e sete homens, distribuídos em sete famílias. Destas, em quatro delas os filhos migraram ou moram em casa, mas exercem atividades no setor secundário ou terciário, enquanto os pais permanecem sozinhos na atividade agroecológica. Em uma propriedade atuam a mãe viúva e o filho solteiro; em outra, a mãe e a nora; e em outra família vivem o casal e dois filhos homens. Os dados evidenciam que na totalidade, as filhas mulheres migraram da agricultura. A Associação está integrada à Rede de Certificação Ecovida - composta de agricultores familiares, técnicos e consumidores reunidos em associações, cooperativas e grupos informais, juntamente com pequenas agroindústrias, comerciantes ecológicos e pessoas comprometidas com o desenvolvimento da agroecologia, - que reúne as associações ou grupos de produtores agroecológicos e certifica a produção dentro desse sistema. A mesma Rede realiza uma reunião ordinária, sempre na primeira segunda-feira do mês de forma itinerante nas propriedades. 
Nesse espaço empírico desenvolveu-se um estudo de caso (YIN, 2001), de natureza qualitativa (BOGDAN; BIKLEN, 1994; ALVES-MAZOTTI, 1998), por apresentar uma tentativa de compreensão detalhada dos significados e características de situações apresentadas pelos investigadores. Consiste em um estudo de caráter etnográfico (LAPLANTINE, 1993) cujo pressuposto é identificar os atributos de gênero diante da questão da transição agroecológica, dos rearranjos familiares e da manutenção das relações produtivas no campo, junto à APASF em Atalanta (SC). Assim, investigaremos o problema em seu ambiente natural considerando a fonte direta dos dados, e como eles se manifestam nas interações entre os pesquisadores e os sujeitos da pesquisa.

Os dados coletados no mês de dezembro de 2014 foram obtidos através da utilização de técnicas como a observação participante e a entrevista semiestruturada. Nomes diferentes e fictícios foram utilizados na transcrição das entrevistas a fim de manter o anonimato dos entrevistados. Na transcrição das entrevistas, respeitou-se ao máximo a originalidade das falas - isso, referindo-se às práticas realizadas com membros atuantes da Associação. Optou-se por utilizar a entrevista não estruturada com 10 membros (homens e mulheres) da Associação, haja vista o interesse por parte dos pesquisadores nos próprios relatos, experiências e perspectivas dos associados. Os registros da observação participante ainda visaram descrever e compreender o que estava ocorrendo em determinadas situações nas propriedades visitadas e reuniões da APASF.

Posteriormente à obtenção dos dados, os mesmos foram analisados utilizando os procedimentos da Análise Textual Discursiva (ATD) de Moraes e Galiazzi (2011), entendida como uma metodologia de análise de dados de informação de natureza qualitativa que objetiva produzir novas compreensões sobre fenômenos e discursos.

\section{As mulheres e as relações produtivas e familiares na ASPAF}

Falta de perspectiva e desestímulo em continuar a cultivar a terra. Era esse o contexto existente na década de 1990, em que algumas famílias no pequeno município de Atalanta (SC), cansadas de sucessivas safras sem êxito e com problemas de saúde relacionados ao uso de defensivos sintéticos, resolveram experimentar um modelo alternativo de produção agrícola: a agroecologia. A fala de Maria trouxe à baila 0 contexto da agroecologia na propriedade e os motivos que fizeram a família optar por este segmento. Segundo ela, a proposta foi recebida com precaução. Afinal, trabalharam a vida toda da mesma forma, e a mudança gerou insegurança:

Meu marido estava com problemas de saúde devido aos venenos. Nós não víamos mais perspectiva de lucro. Mas também não queria sair pra cidade, conhecemos todo mundo aqui, temos nossas coisas, nossa casa que com suor do trabalho conseguimos adquirir. Mas as safras não davam lucro e a gente estava desanimado. Foi então que surgiu a proposta de produzir na agroecologia e eu disse que essa era nossa chance de mudar de vida, de virar a página. Mas a gente não sabia como ia ser (Maria, 53anos. Entrevista concedida em 21 dez. 2014).

A participação feminina no processo de criação da Associação teve fundamental importância. Elas propuseram aos seus maridos a adesão ao novo sistema e os convenceram de que essa poderia ser a saída para não terem que abandonar a agricultura e manter as relações produtivas no campo. Mas, para isso, não poderiam trabalhar individualmente. Ou seja, cada família produzir o que quisesse. Era necessário combinar com os demais membros a quantidade e a espécie a ser plantado, o preço a ser comercializado, entre outros. No entanto, foi necessário que se quebrassem velhos paradigmas da agricultura, como a ampliação da visibilidade do trabalho feminino (PAULILO, 1987; WOORTTMAN, 1995; CARNEIRO, 2001). João destacou a importância que as mulheres tiveram para a 
concretização da associação e para que pudessem adotar o sistema agroecológico:

Eu não acreditei que ia dar certo a gente mudar pra agroecologia. Aceitei por que não via outra forma de nós se manter na roça produzindo e por que a Maria insistiu muito. Eu estranhei muito esta coisa de combinar com outras pessoas o que plantar, vender, etc. Eu estava acostumado a mandar sozinho em tudo. Era eu quem decidia o que plantar, a hora de colher ou vender. Agora a gente ter que ser parceiro das outras famílias, antes, parece que a gente competia. (João, 60 anos. Entrevista cedida em 14 dez 2014).

Ainda na perspectiva da atuação feminina na APASF, os depoimentos revelaram mudança na própria concepção que as mulheres tinham de si e de suas limitações. Como é o caso do depoimento abaixo:

Minha vida mudou muito depois que mudamos para agroecologia. Eu nunca imaginei que pudesse me tornar mais independente. Eu fui criada para ser a esposa. Como a gente morava no interior e não podia estudar mais que a quarta série, aprendi que deveria ser uma boa dona de casa e ajudar o marido na roça. Hoje eu vejo de uma forma diferente. Não me considero ajudante dele. Nós dois somos os responsáveis sobre tudo o que acontece na propriedade, inclusive sobre o dinheiro, sobre o que comprar ou vender. Onde gastar. Percebo que minha em minha casa as coisas mudaram bastante e meu marido também percebeu isto. Em outras casas vejo que ainda existe uma certa resistência dos maridos neste sentido (Gorete, 54 anos. Entrevista cedida em 07 dez. 2014).

A mudança no modo de se relacionar com a própria realidade não foi percebida apenas por elas; os maridos também perceberam o empoderamento, semelhante ao que destaca Assis (2004), onde o termo empoderamento é utilizado por feministas e estudiosas da questão de gênero para referir-se mais ao processo de maior participação das mulheres na esfera pública principalmente política: partidos, sindicatos, associações. Tal empoderamento é percebido gradativamente pelas mulheres e esposas dos homens da associação ao longo do tempo. Os relatos evidenciam que eles também consideram positiva a mudança. José afirmou:
Minha mulher não é mais a mesma. Ela hoje conversa com todo mundo, entende mais as coisas. Nós temos uma relação de igual pra igual. Ela está mais disposta. Eu percebo que com a agroecologia ela se sente mais importante por que as pessoas fazem com que ela se sinta assim. No dia de feira, se ela não vai, os clientes já ficam perguntando o que aconteceu. Quando vem as pessoas visitar a nossa propriedade, ela até se arruma um pouco e vai recebendo o pessoal. Quando recebe um elogio, ela fica toda boba. Gosto de ver ela assim, satisfeita com o que faz. Nem doente ela fica mais. Até eu mudei o jeito de tratar ela (José 47 anos. Entrevista cedida em 12 dez. 2014).

Os depoimentos mostraram também a percepção que as mulheres têm sobre seu trabalho na agroecologia. Para elas, a mudança na forma de cultivar alterou, inclusive, a forma como seu trabalho passou a ser reconhecido dentro e fora das propriedades. Ao serem indagadas sobre quem gosta mais da agroecologia, elas ou seus esposos, as respostas foram unânimes: são elas. Dentre os motivos destacados está a visibilidade que o trabalho ganha. Nesse sentido, Verônica afirma:

Eu sempre gostei mais da agroecologia do que o Pedro. Eu era a responsável pela horta e fazia as geleias aqui para nossa casa. Agora parece que me trabalho aparece mais, tem importância. Antes eu não me achava importante por que parece que eu ajudava o Pedro, agora não. Como sou eu quem faço as geleias, ele é que me ajuda, por que parte da nossa renda vem delas e ele teve que aprender a respeitar isso. Agora às vezes parece que está invertido, ele é que me ajuda. Sei que esta mudança incomoda o Pedro. Eu até entendo, por que ele foi criado de outro jeito. Mas ele sabe que nossa vida mudou pra melhor. Que agora temos renda de maneira mais tranquila e maior parte vem das geleias que eu faço. Ele sabe que a gente só tá na roça por que eu insisti pra nós experimentar a agroecologia e por que eu já conhecia umas técnicas que nós usamos agora. (Verônica, 62 anos. Entrevista cedida em 18dez. 2014).

Corroborando a fala de Madalena, Tereza expõe o que mudou na sua percepção em relação a sua vida após adotar a agroecologia e fazer parte da APASF.

Antes de fazer parte da Associação, minha vida era o serviço da roça e o de casa e às vezes passear na casa dos parentes, ir na missa. Dependia da vontade do marido para ir pra qualquer lugar. Agora não. Eu aprendi a 
dirigir, quando quero ir à algum lugar combino com ele e vou. Temos conta em conjunto, vou no banco, converso com outras pessoas, faço cursos que me interessam. Se eu vejo algo que eu gosto pra mim, pra casa eu compro. Agora parece que a produção é nossa. Antes parecia que era dele Parece engraçado, por que o que faço agora é o que eu via meu pai e meus irmãos fazerem. Não posso reclamar do meu marido, mas as coisas estão muito melhores agora. (Tereza, 70 anos. Entrevista cedida em 20 dez. 2014).

Cabe aqui destacar que a inserção das mulheres rurais no campo político (sindicatos, associações, movimentos sociais, partidos políticos) tem possibilitado um aprendizado coletivo (SPANEVELLO, 2008). Em contexto semelhante, Basquerote Silva (2013) destaca que a APASF é um exemplo, pois circular no espaço público através de viagens e ainda participar em feiras, transitando para além dos limites da propriedade são processos importantes que possibilitam maior igualdade de gênero no campo, na medida em que permitem a elas descortinar a esfera pública e vivenciar diferentes realidades. Nesse sentido, não é apenas a agroecologia o fator catalisador das mudanças para as mulheres do campo em Atalanta, ou em outras regiões. Embora predominem assimetrias nas relações entre mulheres e homens no campo, têm ocorrido processos significativos de mudanças nessas relações.

Há que se mencionar que as relações de gênero nas famílias se tornaram menos assimétricas, mas ainda estão longe de serem ideais ou talvez nunca o sejam. As desigualdades historicamente cristalizadas não são desconstruídas com tanta facilidade. Em contrapartida à aceitação percebida até então, os relatos indicaram que a presença atuante é a participação feminina na APASF, isso não bem aceito por todos os homens.

$\mathrm{Na}$ minha família as relações estão muito melhores do que já foram. Eu sei que meu marido foi educado para ser o "chefe da casa". Na família dele homem não podia fazer o serviço doméstico. Como minha sogra dizia: "O homem veste as calça". Mudar estes conceitos leva tempo. Mas aos poucos vai melhorando. Na Associação, no começo a gente sentia que eles em geral, não gostavam que a gente desse opinião. Um homem

\begin{abstract}
mesmo, sempre dizia que não era bem assim e principalmente pra assumir os cargos de direção. Ele dizia que era melhor que fossem os homens para coordenar, por que as pessoas dão mais credibilidade quando é um homem. Daí que eu fazia questão de que minha voz fosse ouvida. Quando a gente fazia feira junto, ele detestava que eu vendia mais que ele, por que eu agrado as pessoas, sou educada e gentil. Não gosto de resolver as coisas com grosseria. (Ana 55 anos. Entrevista cedida em 12 dez. 2014)
\end{abstract}

Desde o início das atividades de feira as mulheres eram atuantes. Para elas, participar da agroecologia proporcionou um espaço para mostrar à sociedade o que elas são capazes de produzir e a forma como produzem. As conversas explicitaram que elas têm consciência da visibilidade e da contribuição que seu trabalho possui dentro e fora de suas propriedades, quando relatam situações que acontecem nos pontos de venda (feiras):

\begin{abstract}
A feira foi uma grande mudança na minha vida. Antes eu só trabalhava na roça e vinha pra casa, cuidava dos bichos, tirava o leite conversava com alguém diferente quando ia à missa ou ia pra cidade. Minha rotina era essa. Hoje não. Eu saio de casa, converso com outras pessoas, sei dos assuntos, vejo como os outros se comportam, se vestem, tenho amigos que nunca imaginei ter. Me sinto gente. Gosto do que eu faço e vejo que as pessoas valorizam isso. Por causa da feira, até fiz uma conta no facebook e tenho email. Meus clientes me mandam mensagens, fazem encomendas e isso até facilita meu trabalho porque posso levar separado o que eles querem e desse modo não preciso pesar na hora da venda, por exemplo.( Maria, 50 anos. Entrevista cedida em 14 dez. 2014) .
\end{abstract}

Constatou-se que a presença das mulheres na feira proporcionou a elas transitar no espaço público. A Figura 1, posterior e esta reflexão, retrata uma destas formas de participação. Salienta-se que a organização dos produtos na banca da feira põe em destaque a produção das geleias, que são de responsabilidade feminina. Ou seja, são os produtos resultantes de suas atividades que se destacam e materializam sua participação em atividades de produção, de geração de renda e de relações sociais. 
Figura 1 - Feira da APASF com destaque feminino na comercialização.

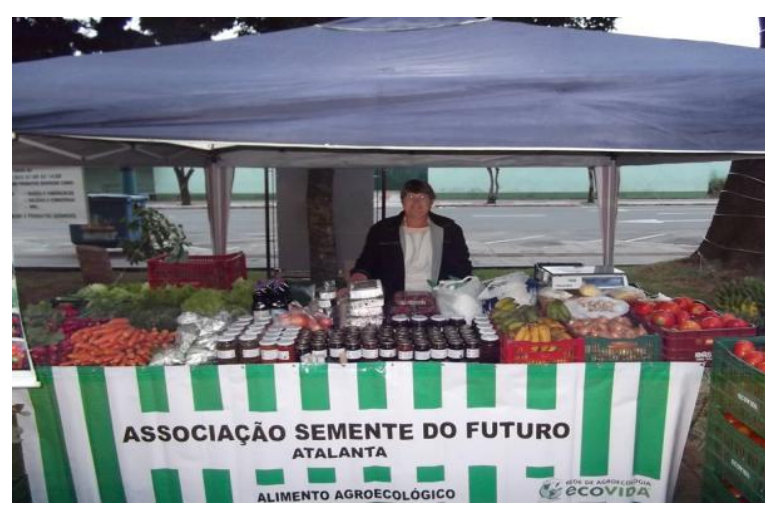

Fonte: Arquivo pessoal dos autores. (Pesquisa de campo. dez.2014).

A participação das mulheres na feira também é percebida pelos homens. O relato de Pedro traz à tona o contexto da feira onde atua junto com Maria, sua cunhada:

\begin{abstract}
Nossos clientes gostam de ser atendidos pela Maria. Ela é simpática, agradável, conhece bem os produtos e conhece até receita para ensinar. Antes da agroecologia ela era diferente. Eu sei por que somos parentes. Ela conversa, com os clientes sobre vários assuntos, como saúde, economia, meio ambiente, relações de gênero, entre outros. Até aprendeu informática pra se comunicar com os fregueses. O dia que ela não vai, os clientes ficam perguntando o que aconteceu com ela. Minha mulher não vem comigo na feira, prefere ficar em casa cuidando das coisas por lá. Ela é mais tímida, mas garanto que se participasse da feira iria ser desinibida. (Pedro, 45anos. Entrevista cedida em $15 \mathrm{dez}$. 2014).
\end{abstract}

O cenário descrito anteriormente avaliza as constatações de Basquerote Silva (2013), Lovato et al. (2010), Shaarf (2001), entre outros, quando afirmam que a organização e a participação das mulheres rurais têm se ampliado à medida que passam a ser atuantes não apenas nos sindicatos $e$ nos movimentos sociais, mas também e principalmente em associações e grupos de produção que desenvolvem experiências produtivas alternativas em nível das propriedades, tais como: agroecologia; criação de centros de formação; prestação de assessoria técnica e organizativa; formação de espaços de comercialização (feiras, cooperativas, associações) entre outros, gerando 0 seu empoderamento.

Assim sendo, a participação na APASF representou uma mudança na própria concepção que as mulheres tinham de si e de suas limitações, além de oportunizar a elas vivenciar outras experiências. Tereza afirma:

Eu antes parecia um bicho do mato, não sabia conversar, tinha medo do que as pessoas falavam ou achavam de mim. Não falava em público. Aos poucos fui mudando. Até que um dia a associação foi escolhida entre muitas outras para representar a agroecologia em um seminário onde tinham pessoas do Brasil inteiro. Ninguém queria ir e eu disse pra Maria, se tu ir comigo eu vou. Era só gente de empresa, engravatado e a maioria homens e nós umas pobres coitadas, de unha manchada de terra, de mãos grossas de lidar com as ferramentas. Eu até já tinha ido em palestra, mas geralmente eram os homens que falavam. Quando chegou a nossa vez de falar, parece que o meu coração ia sair pela boca. E nós subimos no palco e falamos o que tinha que falar do nosso jeito. Quando terminamos, a plateia nos aplaudiu de pé. Desse dia em diante eu pensei: eu posso, eu sou importante, eu tenho valor (Tereza, 70 anos. Entrevista cedida em 20 dez. 2014).

Constatou-se que a partir das experiências vividas pelas mulheres na APASF, elas puderam dar um novo significado à figura que representam e exercem no espaço doméstico. Agora, precisam desconstruir primeiro as imagens que têm de si mesmas - impostas pela sociedade, assimiladas e reproduzidas por elas - para então buscar uma maior autonomização das formas de sujeição pelo contrato sexual, pela cultura etc. Romper no dia-a-dia e libertar-se desse modelo hegemônico de feminilidade, onde a mulher deve ser doce e passiva (e muitas vezes assexuada), é um grande desafio, pois é uma luta contra essas identidades naturalizadas consideradas fixas, acabadas e impostas, apresentadas ao longo da história como naturais, que não apenas as mulheres da associação, mas nesse caso principalmente estas, se deparam rotineiramente e assim desafiadas em seu cotidiano.

A Figura 2 ilustra a forma como as mulheres passaram a vivenciar realidades anteriormente consideradas distantes, situações vividas até então 
apenas por seus maridos, pais e irmãos. Participar de palestras, cursos, dias de campo, feiras, entre outros, tornaram-se atividades naturais e incorporadas as suas realidades.

Figura 2 - Participação da APASF Seminário Catarinense de Agroecologia e Produção Orgânica

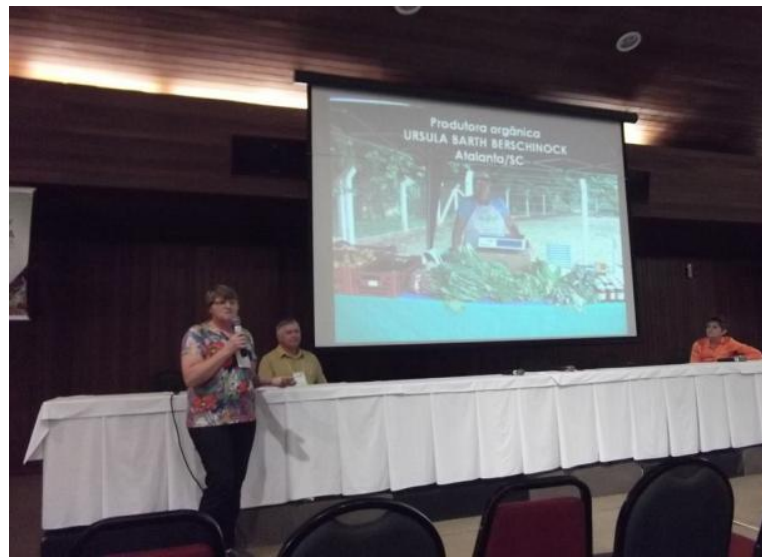

Fonte: Arquivo pessoal dos autores. (Prefeitura municipal de Atalanta, Set. 2014).

No entanto, a inserção em atividades que envolvem eventos externos, ministrar palestras, cursos etc., não se apresenta como uma realidade a todas as mulheres que compõem a APASF; algumas delas são mais inibidas ou não se consideram hábeis para essas atividades.

\section{Considerações finais}

Neste artigo analisamos e identificamos a participação das mulheres agricultoras familiares de base agroecológica na formação, existência e permanência da APASF. Além disso, pôde-se acompanhar a posição que as mulheres tiveram em toda a trajetória da associação, bem como as mudanças decorrentes desse processo para os homens e para elas.

Percebeu-se que para estes agricultores familiares, a agroecologia tem se mostrado uma alternativa viável e promissora, pois tem possibilitado agregação de valor à produção, geração de excedente, maior autonomia produtiva e qualidade de vida dos envolvidos. A formação da associação foi um esforço coletivo de homens e mulheres na busca da permanência no campo.

Evidenciou-se que a adoção do sistema agroecológico de produção resultou em mudança na forma como as próprias mulheres concebiam sua vida, e a partir daí redefiniram sua posição e sua importância na sociedade através do empoderamento gerado a partir da emancipação e da visibilidade que seu trabalho proporciona, por abrir espaços para que elas atuem "sujeitos". Suas conquistas elevaram sua autoestima, diminuíram o preconceito e proporcionaram uma nova forma de organizar as propriedades e de gerir suas vidas.

Além disso, constatou-se mudanças na forma como os homens passaram a perceber as suas companheiras. A partir da agroecologia, as mulheres deixaram de apenas atuar como ajudantes do trabalho de seus esposos. Elas tornaram-se protagonistas e sujeitos do processo produtivo e participam das decisões a serem tomadas nas propriedades.

A análise também revelou haver relações de gênero mais equilibradas a partir da adoção da agroecologia e a criação da APASF. As mulheres que antes exerciam atividades em quase todas as esferas produtivas da propriedade, mas eram responsáveis apenas por aquelas de caráter reprodutivo, deixaram de atuar apenas como ajudantes do trabalho de seus esposos. Elas tornaram-se protagonistas e sujeitos do processo produtivo e participam das decisões a serem tomadas nas propriedades e na Associação. Assim sendo, seu trabalho saiu da invisibilidade e se revelou com uma importante fonte de renda para a família. Além disso, constatou-se mudanças na forma como os homens passaram a perceber as suas companheiras, considerando-as não mais como ajudantes na produção, mas como responsáveis do processo, assim como eles.

Há que se destacar que para estas mulheres, fazer parte da APASF representou muito mais do que uma fonte de renda, denotou participar de um mundo antes apenas idealizado ou vivido por seus esposos, pais irmãos; permitiu avançar para além da esfera 
privada e participar de atividades que ultrapassam o trabalho doméstico ou da lavoura, da realidade vivida cotidianamente, das relações unicamente familiares; oportunizou descortinar a esfera pública por meio da vivência com realidades distintas das suas, na participação em congressos, dias de campo, cursos, palestras, feiras, seminários, viagens, entre outros.

Ademais, evidenciou-se que, por iniciativa feminina, estas famílias mantiveram relações produtivas no campo. Comprovou-se que em virtude dos problemas enfrentados no sistema convencional de cultivo, havia o desejo de abandonar o meio rural e a tendência de não considerar o campo como um lugar de oportunidades. No entanto, a adoção da agroecologia possibilitou às famílias, e em especial para as mulheres, além da permanência nas atividades agrícolas, a ampliação das relações, em virtude do contato com realidades políticas, intelectuais e sociais distintas das vivenciadas até então.

Certamente, muitos são os desafios a serem rompidos por estas mulheres. Mas é inegável a sua ascensão como protagonistas de uma nova forma de fazer, organizar e viver a agricultura familiar e que elas promoveram rearranjos familiares, autonomia econômica, política e social. Por fim, as ações desenvolvidas na APASF demonstram importantes avanços construídos na busca da promoção de igualdade entre homens e mulheres no meio rural, evidenciando que quando as relações de gênero se equilibram, o mesmo ocorre com as relações de poder.

\section{Referências}

ABRAMOVAY, Ricardo et al. Juventude e Agricultura familiar: desafios dos novos padrões. Brasília: Unesco, 1998. 101 p. Disponível em: <http://www.econ.fea.usp.br>. Acesso em: 01 maio. 2014.

Paradigmas do capitalismo agrário em questão. São Paulo: UCITEC/UNICAMP, 1992.

ALTIERI, Miguel. Agroecologia: as bases científicas da agricultura alternativa. Rio de Janeiro: PTA/FASE, 1989.
ASSIS, Gláucia de Oliveira. De Criciúma para o mundo: os novos fluxos da população brasileira e os rearranjos familiares e de gênero. 2004. Tese (Doutorado em Ciências Sociais) - Instituto de Filosofia e Ciências Humanas, Unicamp, Campinas, SP, 2004.

ALVES-MAZZOTTI, Alda Judith; GEWANDSZNAJDER, Fernando. O método nas ciências naturais e sociais: pesquisa quantitativa e qualitativa. São Paulo: Pioneira, 1998.

BASQUEROTE SILVA, Adilson Tadeu. A Participação feminina na agricultura agroecológica: um estudo de caso. In: Fazendo Gênero 10 - Desafios atuais do feminismo. Florianópolis. Anais ..., Florianópolis: UFSC, 2013.

BOGDAN, Robert C.; BIKLEN, Sari K. Investigação qualitativa em educação: uma introdução à teoria e aos métodos. Lisboa: Porto Editora, 1994.

CARNEIRO, Maria José. Herança e identidade de gênero entre agricultores familiares. Estudos feministas, Florianópolis, v. 9, n. 1, 2001.

COSTABEBER, José Antonio; CAPORAL, Francisco Roberto. Possibilidades e alternativas do desenvolvimento rural sustentável. In: VELA, Hugo (Org.) et.al. Agricultura familiar e desenvolvimento rural sustentável no mercosul. Santa Maria, UFSM, 2003. p.157-194.

CAPORAL, Francisco Roberto; COSTABEBER, José Antônio. Agriculturas de base ecológica. In: Agroecologia: alguns conceitos e princípios. Brasília: MDA/SAF/DATER-IICA, 2004. cap. 3, p. 7-11.

GLIESSMANN, S.R. Agroecologia: processos ecológicos em agricultura sustentável. 2. ed. Porto Alegre: Editora da UFRGS, 2001.

HEREDIA, Beatriz Maria Alásia de. A Morada da vida: Trabalho familiar de pequenos produtores do nordeste do Brasil. Rio de Janeiro: Paz e Terra, 1979.

KRAEMER, Osvaldo. Atalanta, Nossa História. Atalanta: 2000.61p.

LAPLANTINE, François. Aprender Antropologia. 6 ed. São Paulo: Brasiliense, 1993.

LAMARCHE, Hugges. (Coord.). A agricultura familiar: Comparação internacional - Do mito à realidade. v. 2. Campinas: Editora da UNICAMP, 1998.

(Coord.) et al. Tradução: Angela Maria Naoko Tijiwa. A Agricultura Familiar: comparação internacional. Campinas: Editora da UNICAMP, 1993.

MAZOYER, Marcel; ROUDART, Laurence. Histoire des agricultures du monde. Du néolithique à la crise contemporaine. Paris, Seuil, 1997.

MELO, Hildete Pereira de; DI SABBATO, Alberto. Mulheres rurais: invisíveis e mal remuneradas. In: 
BRASIL MDA. Gênero, agricultura familiar e reforma agrária no Mercosul. Brasília: Ministério do Desenvolvimento Agrário, 2006. p. 47-87.

MORAES, Roque; GALIAZZI, Maria do Carmo. Análise textual discursiva. 2.ed. Ijuí: Unijuí, 2011.

MOURA, Margarida Maria de. Os herdeiros da terra: parentesco e herança. São Paulo: Hucitec, 1978.

PACHECO, Maria Emília Lisboa. Agricultura Familiar: sustentabilidade ambiental e igualdade de gênero. In: Perspectivas de Gênero: Debates e questões para as ONGs. Recife: GTGênero. Plataforma de Contrapartes Novib / SOS CORPO Gênero e Cidadania, 2002. p. 138-161.

PAULILO, Maria Ignez. O peso do trabalho leve. Ciência Hoje, v. 5, n. 28, p. 1-7, 1987. Disponível em: $<$ http://nafa.paginas.ufsc.br/files/2010/09/OPesodoTra balhoLeve.pdf>. Acesso em: 29 maio 2015.

SAMPEDRO GALLEGO, Rosario. Mujeres del campo: los conflictos de género como elemento de transformación social del mundo rural. In: LEON, M. A. G. (org.) El campo, la ciudad: Sociedad rural y cambio social en España. Madrid: Ministerio da Agricultura, 1996.

SCHNEIDER, Sergio. A Pluriatividade na Agricultura Familiar. Porto Alegre: Ed. UFRGS, 2003.

SPANEVELLO, Rosani Marisa. $A$ dinâmica sucessória na agricultura familiar. 2008. 223f. Tese (Doutor em Desenvolvimento rural) - Programa de Pós-graduação em Desenvolvimento Rural, Universidade Federal do Rio Grande do Sul, Porto Alegre, 2008.

VEIGA, José E. O desenvolvimento Agrícola: uma visão histórica. São Paulo: Hucitec, 1991

A dimensão rural do Brasil. São Paulo: FEA-USP,
2004 Disponível <http://www.econ.fea.usp.br/seminários/artigos> acesso em: 21 maio 2015.

WANDERLEY, Maria de Nazareth Baudel. A sociologia rural na América Latina: produção de conhecimento e compromisso com a sociedade. Revista Alasru, n. 5, 2011, p. 17-45.Disponível http://www.alasru.org/wp-

content/uploads/2011/06/ALASRU2010Revista.pdf. Acesso em: 05 MAIO. 2015.

Raízes Históricas do Campesinato Brasileiro. In: TEDESCO, João Carlos (Org.). Agricultura Familiar Realidades e Perspectivas. 3. ed. Passo Fundo: EDIUPF, 2001a, p. 21-55.

WOORTMANN. Ellen. Herdeiros parentes e compadres: colonos do Sul do Brasil e sitiantes do Nordeste. São Paulo: Hucitec; Brasilia: Editora da UNB, 1995.
WOORTMANN, Ellen; WOORTMANN, Klass. O trabalho da terra: a lógica e a simbólica da lavoura camponesa. Brasília, DF: Editora da UNB, 1997.

YIN, Robert K. Estudo de caso: Planejamento e métodos. Tradução Daniel Grassi. 2 ed. Porto Alegre: Bookmann, 2001. 